\section{Educaçäe
Por Escrito}

SEÇÃO LIVRE

\section{Editor}

Maria Inês Côrte Vitoria

PUCRS, RS, Brasil

\section{Equipe Editorial}

Pricila Kohls dos Santos

PUCRS, RS, Brasil

Marcelo Oliveira da Silva

PUCRS, RS, Brasil

Carla Spagnolo

PUCRS, RS, Brasil

Rosa Maria Rigo

PUCRS, RS, Brasil

\title{
Consciência fonológica na alfabetização de jovens e adultos: como esta relação é concebida pelos alfabetizadores
}

\author{
Phonological awareness in literacy of youth and adults: \\ how this relation is conceived by literacy teachers
}

\section{Luiza de Salles Juchemª, Doris Pires Vargas Bolzan ${ }^{\mathrm{b}}$}

RESUMO: Alfabetizar jovens e adultos abrange variados aspectos biopsicossociais, desafiando a formação dos alfabetizadores para enfrentarem as adversidades que surgem. Ao mesmo tempo, as especificidades relativas ao funcionamento do sistema de escrita alfabética urgem ser exploradas nesse processo de alfabetização. Dentre elas, chamamos a atenção para a consciência fonológica, a qual possibilita ao alfabetizando compreender as relações entre a escrita e os sons que fala. Assim, visamos problematizar concepções de cinco alfabetizadores acerca da consciência fonológica no processo de alfabetização de jovens e adultos. A partir de entrevistas semiestruturadas, baseadas em uma abordagem narrativa sociocultural, realizamos a análise das narrativas e evidenciamos que as concepções dos alfabetizadores são permeadas por uma incipiência teórico-metodológica, que os leva a protelar o trabalho metalinguístico (espera) e, quando promovem atividades dessa natureza, baseiam-se na empiria, improviso e ausência de planejamento (tateamento). Ainda assim, observamos que reconhecem a importância da consciência fonológica à alfabetização de jovens e adultos (valorização). Ressaltamos a necessidade de conhecimentos do campo da linguística, incluindo a consciência fonológica, fazerem parte do rol formativo de alfabetizadores de jovens e adultos, com vistas a uma efetiva aprendizagem sobre funcionamento do sistema de escrita alfabética por esse grupo de estudantes.

Palavras-chave: alfabetização; educação de jovens e adultos; consciência fonológica; ensino do sistema de escrita alfabética.

ABSTRACT: The teaching of reading and writing for youth and adults covers several biopsychosocial aspects, challenging the formation of the literacy teachers to face the adversities that arise. At the same time, the specifities related to the functioning of the alphabetic writing system urge to be explored in this process of literacy. Among

\footnotetext{
a Fonoaudióloga. Doutora em Educação/Universidade Federal de Santa Maria (UFSM). Mestre em Distúrbios da Comunicação Humana/UFSM. <luizasj@hotmail.com>.

b Doutora. Professora Associada do Departamento de Metodologia do Ensino e do Programa de Pós-Graduação em Educação do Centro de Educação/UFSM. Pesquisador Produtividade e Pesquisa CNPq. <dbolzan19@gmail.com>.
} 
them, we call the attention to the phonological awareness, which allows to the literate comprehend the relations between writing and speech sounds. Thus, we aim to problematize conceptions of five literacy teachers about the phonological awareness in the process of literacy of youth and adults. From semi-structured interviews, based on a sociocultural narrative approach, we performed the analysis of the narratives and we evidenced that the conceptions of the literacy teachers are permeated by a theoretical-methodological incipience, which makes them delay the metalinguistic work (delay) and, when they promote activities of this nature, they base themselves on empiricism, improvisation and absence of planning (groping). Even so, we observed that they recognize the importance of phonological awareness to literacy of youth and adults (valorization). We highlight the necessity of knowledge in the fields of linguistics, including the phonological awareness, to be part of the formative list of literacy teachers of youth and adults, aiming some effective learning about the functioning of the alphabetical writing system by these group of students.

Keywords: literacy; education of youth and adults; phonological awareness; teaching of alphabetic writing system; alphabetic writing system.

\section{Introdução}

$\mathrm{O}$

processo de alfabetização de jovens e adultos abrange uma série de aspectos que são específicos da idade adulta e que precisam ser considerados na organização do trabalho pedagógico, como o conhecimento de mundo por eles construído, as tentativas pregressas de alfabetização e as marcas deixadas, as atitudes ante situações que demandam ler e/ ou escrever, as atribuições diárias dos adultos trabalhadores, os conhecimentos já construídos sobre o sistema de escrita, entre tantos aspectos.

No entanto, algumas especificidades relativas ao funcionamento do sistema de escrita alfabética urgem ser exploradas nesse processo de alfabetização. Dentre elas, chamamos a atenção para a necessidade de se ter consciência de que a escrita está diretamente relacionada a sons. Se, para nós leitores essa relação é óbvia, para muitos não alfabetizados não o é. E desconhecer esta informação pode ser um fator impeditivo à sua inserção na leitura e na escrita. Assim, algumas habilidades de consciência fonológica são essenciais à compreensão e à autonomia no uso do sistema de escrita alfabética.

Ao passo que a alfabetização de jovens e adultos coloca à prova a formação dos alfabetizadores, por abranger uma série de aspectos biopsicossociais, além dos específicos da apropriação da leitura e da escrita, sabemos que são restritas as oportunidades formativas por meio de cursos de graduação e pós graduação, que respaldem o trabalho docente na Educação de Jovens e Adultos. Somado a isto, o acesso à alfabetização aos jovens e adultos tem ocorrido, 
principalmente, por meio de programas governamentais de caráter compensatório, em que os professores nem sempre são graduados e tampouco dispõem de subsídios teórico metodológicos suficientes para alfabetizar.

Frente a estas situações, buscamos, neste artigo, problematizar concepções de um grupo de alfabetizadores de jovens e adultos no que concerne à relação entre consciência fonológica e o processo de alfabetização de jovens e adultos. Como enfoque metodológico, realizamos uma reflexão acerca do material obtido na pesquisa originária da tese de doutorado de uma das autoras ${ }^{1}$. Estudo, este, qualitativo, realizado por meio da abordagem narrativa sociocultural, cujo objetivo foi compreender as concepções de um grupo de professores participantes do Programa Brasil Alfabetizado (PBA), do município de Santa Maria/RS, quanto à alfabetização de jovens e adultos e à consciência fonológica neste processo. Como instrumento à obtenção de dados, realizamos entrevistas semiestruturadas com cinco alfabetizadores de jovens e adultos vinculados ao PBA, no município de Santa Maria, no ano de 2013.

\section{A consciência fonológica e a alfabetização de jovens e adultos}

A consciência fonológica consiste em um conjunto de habilidades metalinguísticas que permite aos seres humanos direcionarem sua atenção a diferentes extensões de segmentos sonoros da fala, a refletirem sobre os mesmos, a identificá-los e a manipulá-los, de forma intencional. Ferreiro (2003) complementa, referindo que esta capacidade é a que nos permite entender a maneira pela qual a linguagem oral pode ser decomposta em elementos cada vez menores, ou seja, as sentenças em palavras, as palavras em sílabas e as sílabas, em fonemas.

Embora a maioria dos indivíduos consiga usar palavras como bote e bode sem se confundir, não significa que todos consigam tomar essas palavras como objeto de análise e, de forma explícita, observar, por exemplo, "que são parecidas", "que têm dois pedaços quando falamos", ou que "começam parecido, porque tem o mesmo pedaço /bo/" (MORAIS, 2007, p. 158). Estas capacidades dependem de algumas habilidades de consciência fonológica.

Apostamos na consciência fonológica como uma ferramenta necessária à compreensão das relações existentes entre a escrita e aquilo que ela nota, uma vez que o sistema de escrita alfabética está fundamentado na representação gráfica de unidades da fala. Nesse sentido, Albuquerque (2007) auxilia-nos a pensar na alfabetização de jovens e adultos como uma construção que precisa envolver seus usos e funções sociais, sem negligenciar com o funcionamento do sistema de escrita, o qual depende das capacidade de relacionar a escrita com a pauta sonora.

Com o intuito de compreender as concepções do grupo de alfabetizadores participantes da pesquisa, acerca da consciência fonológica no processo de alfabetização de jovens e adultos, analisamos suas narrativas e as categorizamos em 3 elementos: espera, o tateamento e valorização. 
No que concerne à atitude dos professores ante à habilidade dos alfabetizandos de refletirem intencionalmente sobre os sons, observamos uma aproximação entre suas concepções favorável à espera pelo despertar espontâneo desta capacidade. Ou seja, com exceção de um alfabetizador, os demais não apenas se abstiveram de trabalhar com a reflexão fonológica, como evitaram promover qualquer tipo de ação passível de antecipar a descoberta, pelos estudantes, da relação que existe entre escrita e pauta sonora.

A atitude passiva, de espreita do professor, ao surgimento espontâneo da capacidade dos estudantes em refletir sobre o aspecto fonológico das palavras, fica evidenciada no recorte que segue:

Quando eles fazem isso*, eles estão muito bem, mas demora. [*dizer outras palavras que iniciem como o próprio nome] [...] com o tempo ele se dá por conta, mas é automático isso, e não é tu que quer, é o ser humano, ele tem isso dentro dele, quando vê ele ** [**estalou os dedos] Quando ele descobre aquilo ali, ele "explode" (Professor S).

Ao mesmo tempo que o professor demonstra aguardar a maturidade do alfabetizando antes de intervir, ele é capaz de reconhecer o quanto é satisfatório para o estudante desvendar o funcionamento do sistema alfabético e conquistar autonomia metacognitiva para manipular mentalmente com palavras conhecidas.

[...] quando começa o processo da leitura [...] ele já vai querendo descobrir, "mas que letra começa o meu nome?" por exemplo, essa letra "P" Paulo começa o meu nome [...] que letra é aquela? qual é o som? então eles perguntam quando eles já estão descobrindo a leitura, quando eles identificam o alfabeto... (Professor F).

Esta situação chama-nos a atenção, pois o professor parece atribuir somente ao desejo dos próprios estudantes a descoberta da relação existente entre escrita e pauta sonora. Corrobora com a tendência observada, em que não há intencionalidade no trabalho pedagógico que vise explicitar as características fonológicas do sistema de escrita alfabética desde o início da alfabetização.

Por se tratar de um sistema representacional, o sistema alfabético precisa ser elaborado mentalmente para ser reconstruído no intelecto de cada alfabetizando. Assim, não há razão que justifique um trabalho envolvendo a aprendizagem da escrita do nome próprio por meio da cópia, sem promover algum tipo de reflexão fonológica, tampouco esperar pelo despertar solitário dos alfabetizandos para esta elaboração, mas, sim, que sejam aproveitadas "as oportunidades para fornecer, desde cedo, uma ajuda sistemática que propicie ao aprendiz interagir com a língua numa perspectiva reflexiva” (MORAIS; ALBUQUERQUE, 2010, p. 70). 
Concordamos com o alerta de Morais e Albuquerque (2010) ao referirem que "não se trata de isolar fonemas para que os alunos memorizem os grafemas a eles correspondentes em nossa língua" (p. 71), mas a proposição de atividades envolvendo a reflexão fonológica sobre as palavras, demonstrando aos estudantes que existem palavras maiores que outras, que a extensão sonora influencia na extensão escrita; que algumas palavras rimam e que esta semelhança sonora tem implicação na escrita; que certas palavras têm elementos iniciais parecidos, cujas escritas, na maioria dos casos, também respeitam esta semelhança, dentre outros aspectos.

Nesse sentido, Leal (2010) corrobora, enfatizando a importância de sistematizar o ensino quando o assunto é a aprendizagem dos princípios básicos do sistema alfabético, referindo que

é imprescindível, no processo pedagógico que nós, professores, planejemos nossa ação considerando os princípios teórico-metodológicos que desejamos adotar, os conhecimentos já construídos pelos alunos, dento e fora da escola sobre o objeto de ensino e a natureza do conhecimento a ser abordado. Assim, buscaremos refletir sobre a aprendizagem dos princípios básicos do sistema alfabético, apontando a necessidade de articular de modo coerente nossos conhecimentos sobre esse objeto de ensino e aprendizagem, o sistema alfabético, os modos de apropriação desse conhecimento pelos alunos e a intervenção pedagógica propriamente dita (p. 77).

Entre os professores colaboradores de nosso estudo, além da tendência de conceber como um passe de mágica o despertar dos estudantes para a relação que a escrita reserva com os sons, mostram-se desfavoráveis a um trabalho mais sistemático envolvendo escrita e pauta sonora antes de os estudantes "despertarem" para a existência tal relação, postergando a proposição de atividades de reflexão fonológica.

Conforme o nível que ele está, se tu trabalhar isso tu confundes ele [...] tu tens que estar ciente do teu trabalho. Tudo tem a sua hora mesmo. [...] quando chega lá pela metade em diante que dá para trabalhar: bo-la-cha. Antes tu só vai... ele vai pegar as palavras e vai começar, a - e - i. A. Ra, ÉRRE- A, ÉRRE, A, entendeu? ele não está ainda naquela parte da... então é preferível tu botar o trem fazendo “iu iu” que é as vogais, ou então "tchictchictchic". Tu tens que levar isso, se tu não fizer isso, o símbolo, o sinal não está registrado, porque é preciso, o mundo é esse.. são os sinais e mais sinais, a escrita são símbolos...eu faço [...] mas eu tenho que ter cuidado com quem eu estou. Lembra que eu disse para ti que todos não são iguais? tem uns que já tem essa condição [...] outros não [...] (Professor S).

O Professor $\mathbf{S}$ faz uma expressiva manifestação a favor do aguardar o momento certo para desenvolver a reflexão fonológica de palavras utilizadas na escrita. Ela utiliza a expressão "é uma coisa mútua" para reforçar a sua opinião 
favorável a aguardar o despertar do estudante para só então iniciar o seu trabalho envolvendo o âmbito fonológico das palavras escritas. O professor teme confundir os alfabetizandos caso promova este tipo de reflexão antes de estarem "preparados" para compreendê-la e ainda define o momento em que costuma iniciar essa correspondência, ao citar "lá pela metade em diante".

Ao refletirmos sobre os motivos que podem justificar a espera manifestada pelos professores quanto ao trabalho com a reflexão fonológica, ponderamos sobre a incipiência relativa aos conhecimentos específicos do campo da alfabetização, envolvendo a consciência fonológica, que impedem o trabalho com aspectos linguísticos de forma segura e autônoma pelos professores.

Outro fato que pode justificar muitos professores desprezarem e, em alguns casos, até evitarem o trabalho com sílabas e reflexão fonológica, pode resultar da aversão aos métodos tradicionais e também à ênfase dada às práticas significativas de escrita e leitura, decorrentes do conceito de Letramento. Chegado ao Brasil na década de noventa, O Letramento, termo resultante da tentativa de tradução de literacy, disseminou uma inadequada interpretação do processo de alfabetização. A ênfase às práticas sociais de leitura e de escrita levou muitos professores e estudiosos a acreditar que bastaria o alfabetizando conviver com variados gêneros textuais que construiria noções e hipótese acerca do sistema de escrita suficientes para se alfabetizar.

Somado a isto, a divulgação e a ascensão das descobertas sobre a Psicogênese da Língua Escrita desencadeou uma tendência a evitar os métodos tradicionais de alfabetização e com isso, qualquer tipo de estratégias utilizadas pelos mesmos também passaram a ser negligenciadas. Logo, o trabalho com sílabas e com fonemas, realizado de forma exaustiva e, muitas vezes artificial e sem sentido, nos métodos silábicos e fônicos, respectivamente, acabaram por ser excluídos das práticas de alfabetização. Evitar o trabalho explícito e sistemático de reflexão fonológica pode ser uma maneira encontrada pelos professores para não repetirem intervenções pedagógicas altamente criticadas.

No entanto, acreditamos que não basta a realização de atividades desta natureza para o avanço dos alfabetizandos. A formação dos alfabetizadores de jovens e adultos precisa despertar nestes o hábito da reflexão. Os avanços conquistados na área da alfabetização, incluindo conhecimentos da linguística necessários à apropriação do sistema de escrita alfabética, para serem transpostos para a prática alfabetizadora, demandam do alfabetizador refletir não apenas sobre o processo de aprendizagem do estudante, mas sobre os próprios modelos de alfabetização que sustentam suas práticas.

Conhecer como a consciência fonológica está implicada na evolução das hipóteses de escrita permite ao professor avaliar o que os estudantes desenvolveram em relação a este processo e o que ainda é preciso, de fato, ser contemplado na organização do seu trabalho pedagógico, pois, "o convívio intenso com textos que circulam 
na sociedade não garante que os educandos se apropriem da escrita alfabética, uma vez que essa aprendizagem não é espontânea e requer que o aluno reflita sobre as características do nosso sistema de escrita" (ALBUQUERQUE, 2007 p. 92).

Cabe destacar que somos favoráveis ao trabalho com a consciência fonológica em que esta não se constitua em um pré-requisito para a alfabetização, mas que seu desenvolvimento ocorra simultânea e progressivamente com práticas sociais de leitura e de escrita. As habilidades fonológicas se desenvolvem à medida que os estudantes, em contato com um texto, uma música, verso, poema, são mobilizados a olhar para o interior deles, buscando dissecar as palavras que os constituem, realizando uma reflexão metalinguística, alcançando a especificidade de segmentar as palavras e compreender como são formadas.

Embora muito da curiosidade em compreender a relação entre o oral e o escrito possa partir do alfabetizando, despertar este desejo, mobilizar os sujeitos para essa descoberta, precisa estar entre os objetivos do professor. Nesse sentido, observamos que os professores, após aguardarem a descoberta espontânea pelos alfabetizandos de que a escrita representa sons, eles passam a propor atividades dessa natureza. Ou seja, após os estudantes descobrirem que a escrita representa a pauta sonora das palavras, os professores atuam sobre essa relação. O conjunto de ações trazidas como exemplos, foi denominado de tateamento, uma vez que as atividades de reflexão fonológica promovidas foram baseadas na empiria e no improviso e sem um planejamento prévio que contemplasse as habilidades metafonológicas como uma ferramenta no ensino.

A ausência de um planejamento prévio visando desenvolver a reflexão fonológica, pode ser constatada no seguinte excerto:

"eles chegam assim, como por exemplo, [...] Paulo. O 'pau', ah tem o mesmo som, e aí, se tem o mesmo som, tem as mesmas letras? Essa é a primeira pergunta que eles fazem. Eu digo: eu não sei, vamos ver, vamos escrever, aí ele escreve." (Professor A).

Embora não houvesse menção do alfabetizador sobre o planejamento da atividade com a intenção de provocar a reflexão fonológica, ele soube aproveitar a curiosidade do estudante como uma oportunidade para tal reflexão, associando-a à escrita.

A esse respeito, Freire (2011) destaca a relevância que reside em transformar uma curiosidade que é espontânea em uma curiosidade epistemológica e em provocar os estudantes a acompanharem as reflexões do professor, por meio do compartilhamento destas. O autor complementa o seu pensamento, considerando que 
o bom professor é o que consegue, enquanto fala, trazer o aluno até a intimidade do movimento de seu pensamento. Sua aula é assim um desafio e não uma “cantiga de ninar". Seus alunos cansam, não dormem. Cansam porque acompanham as idas e vindas de seu pensamento, surpreendem suas pausas, suas dúvidas, suas incertezas (p. 83-84).

Para o professor, é essencial refletir sobre o objeto de ensino, no caso o sistema de escrita, a fim de que estabeleça os objetivos didáticos e organize as estratégias das quais irá se utilizar para promovê-los. Nesse sentido, Andrade e Silva (2010, p. 138) citam que "as abordagens mais recentes exigem que o docente planeje o seu ensino de forma a contemplar tanto o domínio do sistema alfabético quanto o trabalho com temáticas envolvendo os mais diversos gêneros textuais (leitura e produção)".

Dentre as atividades envolvendo a reflexão fonológica mencionadas pelos professores colaboradores, preponderam aquelas que objetivam corrigir a maneira de falar de escrever de acordo com as normas cultas da língua, pois, esta é uma preocupação que mobiliza os alfabetizadores.

No que concerne aos usos da reflexão fonológica visando, de forma equivocada, corrigir erros ortográficos que não são motivados pelo apoio na oralidade, mas resultantes de regras arbitrárias de ortografia, como já mencionado, destacamos alguns recortes das narrativas manifestando tais práticas:

[...] teve aluno que escreveu cansada com "Ç" [...] o jogo da memória [...] por exemplo, esse "cansada", eu procurava botar a figura de uma pessoa que representava cansaço [...] (Professor A).

Certas palavras se escreve com um S [esse], com dois S [esses], por que? [...] Eu olhei para eles e disse: acontece que se eu não conseguir fazer essa prática [jogos de memória, caça-palavras] com vocês, vocês não vão descobrir os sons das palavras, ou, se vão descobrir, por exemplo, quando tem dois esses? (Professor E).

Esses recortes de narrativa demonstram a tentativa dos professores de solucionarem uma situação que consideraram problemática, que é a questão ortográfica, e, para tanto, lançaram mão de atividades envolvendo reflexão fonológica associada às palavras escritas, sem ter a clareza do que originava as ditas trocas ortográficas. Em alguns casos, o fato de refletir sobre a oralidade acaba por contaminar a escrita, e tal diferenciação se faz necessária:

[...] quando eu quero [ensinar] as duas vogais juntas ou duas consoantes: o "R" e o "S", eu digo: escuta a tua boca, sente a tua boca, olha o que aconteceu com os teus dentes, agora tu vais saber a diferença se é um " $R$ " ou dois " $R$ ". Quando forem dois " $R$ " ou dois " $S$ " os dentes vão apertar. Capaz professor, é assim que eu vou 
descobrir?. É! A gente tem que fazer alguma coisa, né Luiza? [...] e aí eles falam: “coRRer!!” (com ênfase no som dos dois erres). Tu viu que arranhou tudo e ficou diferente? [professora reproduzindo sua pergunta ao estudante] Até esse recurso é usado (Professor S).

A narrativa do Professor S, em que compara o uso de "SS com o uso de "RR", fazendo alusão à mudança na sonoridade resultante da duplicação dessa consoante e comparando a duplicação do R, demonstra o interesse do professor em ensinar. Entretanto, lança mão da reflexão fonológica para explicar uma arbitrariedade do sistema ortográfico. Exemplificar que a falta de um "R" no substantivo "CARRO" transforma-o no adjetivo "CARO" é uma forma de usar a reflexão fonológica a favor da construção. Por outro lado, tentar demonstrar que a palavra "CANSADA" altera o som fricativo /s/ quando escrito com "ç" ou "s", seria usar a consciência fonológica para confundir o estudante.

Logo, embora reconheçamos a boa intenção dos professores com este tipo de atividade, identificamos que a incipiência em termos de conhecimentos linguísticos os impedem de promover um trabalho efetivo com a reflexão sobre o som das palavras e sobre a diversidade na expressão oral. A falta de subsídios teórico-metodológicos no âmbito da linguagem que permitam o professor diferenciar a motivação dos erros ortográficos, somada à correção apressada e inadequada de tais erros, pode colaborar com a manutenção da dificuldade ao invés de favorecer o avanço dos estudantes.

Para tanto, é necessário

o professor estar consciente das diferenças entre o oral e o escrito para que não invente pronúncias puramente didáticas que não sejam próprias de nenhum grupo social e tampouco discrimine as pronúncias daqueles educandos provenientes de diferentes zonas geográficas, ou seja as diferenças dialetais. o fato de universalizar a fala favoreceria a alguns, mas dificultaria pra outros (FERREIRO, 2001, p. 136-137).

Em nosso estudo, observamos que as práticas envolvendo a metalinguagem, mencionadas pelos alfabetizadores colaboradores, são marcadas pela empiria. Restritas no número de habilidades desenvolvidas e imprecisas quanto às suas formas de trabalhar e finalidades. Do recorte da narrativa do Professor S emergiu nossa observação:

[...] tu sabes trem [...]? tchic-tchic-tchic-tchic? Eu sou muito criança [...]! A palma, eu gosto muito de bater palma, eu mexo muito com barulho, porque eu sei que a audição... eu não sei porquê, mas um está ligado com o outro [...] tem que trabalhar isso com gestos, com outro sinais, [...] tens que mexer com tudo que está em roda [...] encontro de consoante dá bagunça, demora para assimilar. É mais fácil tu encontrares vogais do que consoantes, não sei porquê, mas eu sinto isso (Professor S). 
Na manifestação do Professor S, quando ele exemplifica o tipo de trabalho que realiza com sons, como o "tchic-tchic-tchic-tchic" (som do trem), está lançando mão da repetição sons, monossílabos, em sequência, seguida do seu registro escrito, com o intuito de facilitar a compreensão pelos estudantes da relação entre a pauta sonora e escrita. Observa-se uma manifestação de entusiasmo do professor, entretanto, a escolha de uma onomatopeia para o trabalho com jovens e adultos pode se tornar algo pouco interessante, por partir de uma temática infantil que, provavelmente, não faz parte de suas vidas, como já mencionado anteriormente. Além disto, por não se tratar de uma palavra regular da nossa língua, são distintas as possibilidades de sua produção oral e também escrita, podendo prejudicar a compreensão do funcionamento do SEA pelos estudantes.

Analisando, ainda, a narrativa do Professor $\mathbf{S}$ na expressão "não sei porquê, mas um está ligado com outro" ou "não sei porquê, mas eu sinto isso", fica clara a dúvida e a empiria quando o assunto é reflexão fonológica. Mostra a lacuna de um conhecimento que é fundamental para a apropriação do sistema de escrita. A curiosidade, embora presente, não foi suficientemente mobilizadora a ponto de buscar ser superada. O professor percebe que é importante trabalhar com o som, mas não possui um conhecimento teórico que o respalde a organizar, de forma segura e eficiente, a sua prática, tampouco a criar novas estratégias e direcionar a atenção ao som, relacionando à escrita.

Quando refere que é preciso "mexer com tudo que está em volta", denota um aproveitamento restrito das situações que poderiam ser melhor direcionadas à compreensão do funcionamento da relação entre escrita e pauta sonora, pelos estudantes. Uma provável incipiência quanto ao conhecimento específico desta área acaba por restringir as possibilidades de desenvolvimento das habilidades necessárias à apropriação do sistema de escrita.

O empenho dos professores, em contribuir de alguma maneira com o avanço dos estudantes, embora não resulte de conhecimentos tácitos, demonstra que, de forma unânime, reconhecem a importância de se pensar sobre os sons para produzir a escrita e ser capaz de ler. Dentre as atividades mencionadas, observamos a recorrência do uso do nome próprio como um mobilizador da reflexão fonológica:

Morais, 2010 (p. 74) valoriza o trabalho com palavras estáveis, como, por exemplo, o nome próprio, pelo fato de o estudante ter memorizado a configuração destas, o que lhe traz recursos para refletir sobre as relações parte-todo, a fim de decifrar o enigma daquelas relações: "por que a palavra começa com tal letra e continua com aquelas outras naquela ordem? Por que eu falo tantos pedaços (sílabas) e tem mais letras quando eu escrevo?”.

Destacamos as reflexões de Morais (2012) ao indicar a necessidade do alfabetizador ter clareza sobre quais habilidades são realmente importantes à alfabetização, que não é necessário ter desenvolvido tais habilidades como condição para iniciar o processo de alfabetização e que o "treino" de correspondência entre as letras e segmentos sonoros é insuficiente e inadequado para alfabetizar. 
Em nosso estudo, embora tenhamos identificado fragilidades epistemológicas no embasamento do trabalho com a consciência fonológica, somente foi possível realizar esta análise por podermos contar com exemplos de trabalhos realizados no âmbito sonoro das palavras. Isto nos permite inferir que há uma aposta nesta capacidade, mesmo sem haver segurança sobre como e quando fazê-lo, denotando, portanto, que esses alfabetizadores de jovens e adultos reconhecem a consciência fonológica como relevante à alfabetização deste grupo etário.

Os trabalhos com a consciência fonológica, mencionados pelos professores participantes, embora restritos quanto a habilidades trabalhadas, tardios no seu início e imprecisos quanto ao que visam, ainda assim são promovidos. Assim emergiu o elemento categorial que denominamos valorização, que trata do reconhecimento da importância de habilidades de consciência fonológica no processo de alfabetização de jovens e adultos.

Tu tens que fazer essa associação [entre a escrita e a sonoridade]. É com o tempo que tu vais fazendo essa associação. [...] Isso é importante porque no momento que eles se dão conta que para eles conversarem um com o outro, eles tem que formar palavras e que as palavras são formadas por fonemas [...] aí eles entendem esse nexo de como é que se ligam (Professor I).

Embora não haja menção à sistematicidade no trabalho de reflexão fonológica, há o reconhecimento da importância que reside na associação entre sons e escrita para que os estudantes compreendam o funcionamento do sistema alfabético, admitindo que cabe a si a responsabilidade de instigá-los a fazer tais associações.

Uma outra forma de explorar a faceta sonora das palavras foi explicitada pelo Professor E, que, além de demonstrar a sua valorização quanto à relação entre a escrita e os sons, aborda a forma com que trabalha esta relação:

[...] eu acho importante [o trabalho] sobre os sons [...] A leitura do professor em aula é muito importante. Quando eu ia pra frente do quadro ler um texto, [...] eles já sabiam que era o momento de prestar a atenção na articulação das palavras, dos sons... (Professor E).

O Professor E explora a faceta auditiva das palavras por meio de uma leitura em voz alta realizada por ele próprio. Assim, embora a intenção pareça ser a de possibilitar aos estudantes o contato com uma forma culta de falar/ ler, demonstra, desta forma, valorizar as atividades que relacionam escrita com a pauta sonora.

A valorização desta relação também pode ser observada na narrativa do Professor A, em que enfatiza a intenção de tornar lúdica e prazerosa a atividade que envolve a escrita e seus sons, ao exemplificar uma atividade que proporcionou aos estudantes: 
era assim, "A" de abelha, então eu levava a figura da abelha e a letra "A" e ela montava junto. Vamos fazer um quebra cabeça? Vamos fazer um joguinho de dominó? Era assim que eu montava, que eu combinei de ensinar, com a imagem, porque só o som ele não pega, o aluno tem que ter a imagem [...] Por exemplo, a palavra casa, ela sabe que a palavra casa tem um "A", então eu levava muitas revistas, estas coisas, jornais, aí ela via o desenho de uma casa na revista e eu mandava recortar. [...] eu fui levando as figuras [...] trabalhei letra por letra [...] fui montar o alfabeto com ela através de jogos, porque se o professor atirar o alfabeto para o aluno, ele não aprende (Professor A).

Da narrativa do Professor A podemos depreender que há intenção em mobilizar os alfabetizandos à construção do conhecimento, explicitando o seu cuidado em não "atirar o alfabeto para o aluno" simplesmente. No entanto, proporcionalmente ao reconhecimento da importância de trabalhar com a reflexão fonológica, está a infantilização da prática. Embora não seja o alvo principal deste momento da análise, não pode deixar de ser identificada. Assim, os excertos extraídos das narrativas dos alfabetizadores expressam a necessidade de um trabalho mais sistematizado, envolvendo a reflexão fonológica e demonstram uma preocupação com a maneira de ensinar embora esta receio em encontrar formas adequadas de ensinar não garanta que as tenham encontrado. Mas o cuidado em não deixar somente a cargo dos estudantes o estabelecimento das relações entre o conhecimento das letras e os sons que elas representam já é digno de nota. Este cuidado fica claramente evidenciado na expressão "se o professor atirar o alfabeto para o aluno, ele não aprende", referida pelo Professor A e encontra ressonância no que Freire (2011) preconizou como um cuidado necessário para apreender a substantividade do objeto a ser aprendido:

A memorização mecânica do perfil do objeto não é aprendizado verdadeiro do objeto ou do conteúdo. Neste caso, o aprendiz funciona muito mais como paciente da transferência do objeto ou do conteúdo do que como sujeito crítico, epistemologicamente curioso, que constrói o conhecimento do objeto ou participa de sua construção (p. 67).

Pereira (2007), em seus estudos acerca de práticas educativas de um projeto de alfabetização de jovens e adultos, identificou pouca clareza nos pressupostos metodológicos que fundamentavam o trabalho desenvolvido. Constatou, ainda, que a ausência de uma progressão no grau de complexidade na abordagem do sistema de escrita levou à desmotivação, à baixa assiduidade e à restrita aquisição da escrita pelos estudantes.

Assim, consideramos que a construção de propostas pedagógicas para alfabetizar jovens e adultos necessita partir da valorização dos seus conhecimentos prévios, além de um ensino sistemático quanto ao funcionamento do sistema de escrita. Precisam, ainda, contemplar os anseios dos alfabetizandos. Para isso, além de um diagnóstico 
acerca das experiências, conhecimentos e sobre o que motiva esses sujeitos a ler e a escrever, é imprescindível que conhecimentos específicos do campo da linguística, nos quais inclui-se a consciência fonológica, façam parte do rol formativo dos alfabetizadores.

\section{Apontamentos finais}

Esperamos que, por meio deste artigo, possamos contribuir com as reflexões acerca da formação de professores alfabetizadores de jovens e adultos, corroborando com os estudos que problematizam a qualificação das práticas docentes na modalidade da EJA. Para tanto, trazemos para este diálogo final, algumas indicações a partir deste trabalho:

- A diversificada abrangência da atuação do alfabetizador de jovens e adultos pode resultar no menosprezo do ensino de princípios que são básicos à apropriação da leitura e da escrita. No entanto, a compreensão, pelo estudante, de que a escrita guarda relação com a pauta sonora das palavras, e não com características físicas ou funcionais dos referentes que substituem, precisa estar nos objetivos didáticos do professor. Esta compreensão é fundamental para iniciar um trabalho de alfabetização.

- Os formatos, a ordem, a variedade e a quantidade de letras no interior das palavras; a descoberta de que as letras representam segmentos menores do que sílabas e que seus valores sonoros são fixos, apesar de muitas letras terem mais de um valor sonoro e vice-versa; à existência de outras marcas na escrita, que não apenas letras, que modificam tonicidade ou sons de sílabas e os diferentes tipos de composições de sílabas no português são também aspectos essenciais à apropriação do sistema de escrita alfabética e precisam ser contemplados no seu ensino.

- A distinção entre consciência fonológica e os métodos tradicionais que a utilizam como ferramenta (como os métodos fônicos) é necessária para que os professores tenham segurança em organizar o seu trabalho pedagógico. Só assim podem desenvolver as habilidades que são essenciais à apropriação da escrita, sem desperdiçar tempo e o anseio dos estudantes, trabalhando com habilidades que surgiriam, espontaneamente, com o aumento da interação com a escrita.

- Os subsídios teóricos do campo da linguística fazem-se essenciais aos alfabetizadores, não só de jovens e adultos, mas também de crianças, para que o alfabetizando possa avançar nas hipóteses que traz consigo quanto ao funcionamento do sistema de escrita. De posse de conhecimentos desta área, os professores podem analisar as construções escritas dos estudantes, reconhecê-las como genuínas em suas diferenças e intervir de forma efetiva, ao invés de aguardarem a descoberta solitária do funcionamento do SEA. 
- Os avanços na prática alfabetizadora não acontecem enquanto o professor sente-se confortável com indagações não respondidas e convive amistosamente com elas, sem buscar desvendá-las.

- A configuração de espaços para que a Educação de jovens e adultos seja problematizada, levando em conta os conhecimentos já produzidos na área e é essencial para a qualificação das práticas alfabetizadoras, seja na graduação ou na pós-graduação de professores.

- A identificação e o reconhecimento, pelos coordenadores dos encontros formativos de alfabetizadores, quanto ao que já sabem sobre o funcionamento do sistema de escrita alfabética, relações entre a oralidade e escrita, consciência fonológica e quanto à psicogênese da escrita pode auxiliar tais coordenadores no planejamento focado às necessidades de determinado grupo.

- A compreensão do funcionamento do sistema alfabético de escrita requer interações com pares, com professores e com textos ricos em sentido. Para isso, além da reflexão sobre as características semânticas e ideológicas do que é lido, é necessária a reflexão fonológica sobre o mesmo.

- A realização de atividades sistemáticas de produção da leitura e da escrita é compatível com o desenvolvimento da consciência fonológica, no entanto, não basta o simples experimentar da oralidade, mas tomá-la como suporte para pensar e problematizar o funcionamento da escrita.

- A problematização do cotidiano dos alfabetizandos pode desencadear o interesse pela leitura e a escrita de distintos tipos de textos relacionados à temática de interesse, possibilitando não apenas a ampliação da leitura de mundo, mas servirem como objetos de reflexão fonológica, ampliando sua compreensão sobre o sistema de escrita alfabética.

- As atividades que mobilizam os estudantes a descobrirem a relação existente entre a escrita e a oralidade, como segmentar oralmente a palavra em sílabas, contar quantas sílabas as palavras possuem, compará-las de acordo com sua extensão, semelhanças sonoras iniciais (aliteração) e finais (rimas), visualizar na escrita as características percebidas na oralidade são maneiras de proporcionar que os estudantes interajam com a língua em uma perspectiva reflexiva.

- Os aspectos relativos ao funcionamento do sistema de escrita alfabética que precisam ser compreendidos pelos alfabetizandos demandam do professor um cuidadoso olhar para as conquistas obtidas por eles neste âmbito, a fim poderem organizar estratégias pedagógicas mobilizadoras da progressão dos estudantes nessa descoberta.

- O conhecimento do funcionamento do sistema de escrita alfabética e como a linguística está nele implicada é chave para um trabalho profícuo na alfabetização, a qualquer idade. Baseado na identificação do nível de conhecimento da escrita em que se encontram os alfabetizandos, é que o professor pode provocá-los a 
refletirem sobre suas produções e, por meio de habilidades de consciência fonológica, fazerem associações, cada vez mais autônomas e apropriarem-se, efetivamente, da linguagem escrita.

- Identificar o que está motivando um erro ortográfico depende de conhecimentos específicos do campo da linguística, permitindo evitar correções equivocadas e em momentos inoportunos. Os erros são reveladores de hipóteses elaboradas pelos aprendizes durante o processo de aquisição da escrita. Algumas trocas de letras são motivadas pela oralidade como a escrita "cumida" ao invés de "comida", por exemplo. Este tipo de troca é diferente de escrever "relachado" ao invés de "relaxado". Enquanto alguns erros ortográficos têm motivação fonética/fonológica, outros são originados por arbitrariedades do próprio sistema ortográfico. Logo, não podem ser tratados da mesma maneira.

- A adequação da fala não pode se tornar um pré-requisito para escrever bem, mas, sim, uma consequência do desenvolvimento da leitura e da escrita. Jovens e adultos precisam ser encorajados a expressarem-se, tomando como base, para suas tentativas iniciais de escrita, a sua própria maneira de falar, pois é com esta que estão familiarizados. Não se vislumbra, com isso, a estagnação quanto ao modo de falar ou escrever, mas sim o respeito e o incentivo à expressão de ideias. Após compreendido o funcionamento do sistema de escrita é que a ortografia torna-se alvo do professor.

- Um registro atualizado dos avanços individuais dos estudantes e de seus entendimentos pode auxiliar na decisão do professor sobre quando priorizar a ortografia em detrimento do conteúdo da escrita, a partir de intervenções favoráveis e respeitosas sobre o que já construíram previamente.

- Os alfabetizandos precisam ter oportunidade de escutar suas vozes, expressarem-se, em ambiente amistoso para fazê-lo e ampliá-lo, tanto no nível oral como no escrito. Práticas discursivas dos diferentes grupos sociais necessitam de espaço no processo de ensino e de aprendizagem entre os jovens e adultos.

- A aproximação do alfabetizador aos contextos dos alfabetizandos, identificando os anseios em relação à leitura e à escrita, ao nível de apropriação do sistema alfabético em que se encontram e suas condições de vida, sinaliza comprometimento do professor com a aprendizagem dos estudantes. Essa inserção possibilita mediações pautadas tanto nas construções prévias como na relevância individual atribuída às aprendizagens.

- Os diferentes gêneros textuais, conhecimentos referentes às disciplinas, como ciências, história, geografia e outras, além de servirem como instrumentos de apoio à aprendizagem da leitura e da escrita, devem instigar o desejo dos alfabetizandos em conhecer mais sobre estes campos. A presença de distintos aportes textuais em aula precisa instigá-los a desvendar não apenas demandas imediatas como listas de mercado, receitas culinárias ou letreiros de ônibus, mas instigar o desejo e a curiosidade, favorecendo a inserção social e cultural destes cidadãos, de forma autônoma, na infinidade de leituras que desejarem. 
Por fim, destacamos a relevância dos conhecimentos teóricos do campo da linguística, incluindo a consciência fonológica, fazerem parte da formação dos alfabetizadores, independente da idade dos alfabetizandos com quem irão trabalhar. Estes, por sua vez, precisam ter oportunidade de expressar suas ideias e ouvirem suas vozes. Medidas essas, em prol da qualificação docente e dos espaços de ensino, em qualquer idade, quiçá, podem conter a indesejada realidade de muitos que ainda atingem a idade adulta não alfabetizados.

\section{Referências}

ALBUQUERQUE, Eliana Borges Correia. Alfabetizar sem “bá-bé-bi-bó-bu”: uma prática possível? In: LEAL, Telma Ferraz; ALBUQUERQUE, Eliana Borges Correia (Org.). Desafios da educação de jovens e adultos: construindo práticas de alfabetização, Belo Horizonte: Autêntica, 2007.

ANDRADE, Eliane Nascimento Souza; SILVA, Roseane Pereira. Produção de diferentes gêneros textuais em turmas de alfabetização de jovens e adultos: dificuldades e possibilidades. In: ALBUQUERQUE, Eliana Borges Correia; LEAL, Telma Ferraz (Org.). A alfabetização de jovens e adultos em uma perspectiva de letramento. 3. ed. Belo Horizonte: Autêntica, 2010.

FERREIRO, Emília Escrita e oralidade: unidades, níveis de análise e consciência metalinguística In: FERREIRO, Emília (Org.) Relações de (in)dependência entre oralidade e escrita. Porto Alegre: Artmed, 2003.

FERREIRO, Emília. Cultura escrita e educação: conversas de Emília Ferreiro com José Antônio Castorina, Daneil Goldin e Tosa María Torres. Porto Alegre: Artmed, 2001.

FREIRE, Paulo. Pedagogia da autonomia: saberes necessários à prática educativa. 20. ed. São Paulo: Paz e Terra, 2011.

LEAL, Telma Ferraz. A Aprendizagem dos princípios básicos do sistema alfabético: por que é importante sistematizar o ensino? In: ALBUQUERQUE, Eliana Borges Correia; LEAL, Telma Ferraz (Org.). A alfabetização de jovens e adultos em uma perspectiva de letramento. 3. ed. Belo Horizonte: Autêntica, 2010.

MORAIS, Artur Gomes. Sistema de escrita alfabética: como eu ensino. São Paulo: Melhoramentos, 2012.

MORAIS, Artur Gomes. A consciência fonológica de alfabetizandos jovens e adultos e sua relação com o aprendizado da escrita alfabética. In: LEAL, Telma Ferraz; Albuquerque, Eliana Borges Correia e MORAIS, Artur Gomes. Alfabetizar letrando na EJA: fundamentos teóricos e propostas didáticas. Autêntica, Belo Horizonte, 2010.

MORAIS, Artur Gomes. O desenvolvimento de habilidades de reflexão fonológica em adultos e jovens pouco escolarizados: seu papel no aprendizado do sistema de escrita alfabética. In: LEAL, Telma Ferraz; ALBUQUERQUE, Eliana Borges Correia (Org.). Desafios da Educação de Jovens e Adultos. construindo práticas de alfabetização. Belo Horizonte: Autêntica, 2007. p. 151-172.

MORAIS, Artur Gomes; ALBUQUERQUE, Eliana Borges Correia - Alfabetização e Letramento: o que são? Como se relacionam? Como "alfabetizar letrando". In: ALBUQUERQUE, Eliana Borges Correia; LEAL, Telma Ferraz (Org.). A alfabetização de jovens e adultos em uma perspectiva de letramento. 3. ed. Belo Horizonte: Autêntica, 2010. 
PEREIRA, Marina Lúcia de Carvalho. A construção do letramento na educação de jovens e adultos. 2. ed. Belo Horizonte: Autêntica, 2007. 168 p.

Recebido em: março/2016

Aceito em: novembro/2016

\section{Endereço para correspondência:}

Luiza de Salles Juchem

Rua Duque de Caxias, 1900, ap. 402

97015-190 Santa Maria, RS, Brasil

<luizasj@hotmail.com> 